\title{
Does the Age of an IT Executive Impact Adoption Levels of Cloud Computing Services?
}

\author{
Dr. Marcus L. Smith, Jr. \\ Texas A\&M University - Commerce \\ Commerce, TX 75429, USA
}

\begin{abstract}
This author researched previously the personal decision factors considered by information technology (IT) executives when making the cloud computing services adoptionchoice. The conclusions in that work (Smith, Jr., 2016) supported four hypotheses, namely, (a) advancement, recognition and satisfaction from accomplishments, (b) top management support, $(c)$ diminishment of personal image, and $(d)$ a pattern of technology readiness have a positive influence on business intentions to adopt cloud computing services. Interestingly, a fifth hypothesis, diminishment of personal image, was found to have a negative influence on business intentions. The relationship between age of the survey respondents and adoption levels was highlighted in that dissertation as an area worthy of future research. The study described in this article represents a "deeper dive" into this specific potential correlation. The results of this study may provide greater insights into the challenges sales organizations face when attempting to market their cloud computing services.
\end{abstract}

Keywords: Adoption, Age, Cloud Computing, Correlation, Motivation Theory, Outsource, Risks, Security

\section{Introduction}

Cloud computing has become a generally-accepted platform for outsourced IT operations. According to Dhar, (2012) "Cloud computing is the latest trend to outsource some or complete IT operations to run a business." From its earliest forms of general purposeoutsourced hostingservices (e.g., Software as a Service (SaaS), Platform as a Service (PaaS), and Infrastructure as a Service (IaaS)), cloud is now the hometo other, more sophisticated services for content delivery, automated failovers, and disaster recovery. The demands of customers have caused the breadth of service offerings to grow with new, more specialized cloud computing applications such as Communications as a Service (CaaS), Network as a Service (NaaS), and Storage as a Service (STaaS).

According to Mell \& Grance (2011), all cloud computing services have five common characteristics including:

- on-demand self-service;

- broad network access;

- resource pooling;

- rapid elasticity; and

- measured service.

While these features would suggest a strong justification for moving any or all of a company's applications to the cloud, studies by this and other researchers have found various conditions that are inconsistent with a trend towards cloud adoption. For instance, Prescott (2011) concluded a strong association has existed between business size and the degree to which a company follows an IT strategy that strongly embraces the use of cloud services. Smith \& Gonzalez (2014) found small and medium-sized companies were more likely to adoption cloud solutions than their large and enterprise-sized counterparts. They further contended that cloud computing, in fact, had acquired a low rate of interest within large companies.

Another factor showing similar inconsistencies is business industry. Some industries have shown a strong predilection towards adoption of cloud applications while other industries have been reluctant to migrate to the cloud. This dilemma applies to types of industries as much as it does to specific industries. For instance, Espadanal \& Oliveira (2012) found that the risks associated with cloud-based applications were too high especially for non-IT-centric industries. Later, in 2014, the research of Oliveira, et al. (2014) set forth four reasons why, despite the touted advantages of cloud computing, all companies were not making the adoption decision. These reasons included: (a) cloud had not reached a satisfactory level of maturity, (b) the lack of cloud industry standards, (c) the associated level of related risks, and (d) the associated level of related costs. 


\section{Literature Review}

\subsection{Motivation Theory's Relationship to Age}

Motivation theory helps explain and predict behavior. Consistent with this theory, motive is an element that prompts the behavior of the individual, sometimes as a consequence of experiences. Motivation theory is a heavily studied field of psychological research. Researchers such Deci and Ryan, van der Heijden, Dewett, and Cabanac have made significant contributions to the total body of work on this subject.

Deci and Ryan (1980) found that "intrinsically motivated behaviors are those behaviors that are motivated by the underlying need for competence and self-determination" (p. 42). However, their work suggested a clarification of the definition was necessary for the purpose of their research inasmuch as external contingencies did not affect these behaviors. They concluded also that concerns over job preservation grow with the executive's age to the point that the fifty-and-older group become practically unemployable. This concern may heighten personal fears over the potential of a decision failure. Furthermore, van der Heijden (2002) found:

Upward mobility, in particular, seems to be impossible for many older workers. Fifty-five percent of the employees of 40-52 at the middle level and 40 percent of those at a higher level are considered by their superior to be at "the top of their ability." (p. 48)

Without the motivation of potential advancement, executives in this age group may determine risk taking in the form of introducing a radically new or different technology may be unwise from a personal standpoint.

These conclusions should not come as a surprise considering how other researchers have reached similar conclusions in their studies of the relationship between an executive's age and risk-taking behavior. Lippmann (2008) concluded in his study that workers in the 55-64 age group are more likely to be discharged than younger workers and stand less of a chance of being rehired. Furthermore, Lippmann charges that "older workers suffer greater earnings losses upon reemployment as a result of displacement" (i.e., the new job paid less than the previous job). Similar to Lippmann, Koeber \& Wright (2001) determined that workers in the over-50 category experienced significantly greater financial losses than their 50-and-under counterparts.

In his work, Serfling (2015) found that the executive's age impacts significantly on their risk-taking actions. Hambrick \& Mason (1984) suggested three reasons three reasons why older managers were associated less with taking risks than their younger counterparts: (a) the importance of financial and career security to older managers, (b) a greater commitment to the status quo, and (c) less mental and physical stamina than younger managers. These conclusions could lead an executive to reasonably question the personal benefit from making decisions involving unnecessary risks.

The precepts of agency theory may add to a further appreciation of these phenomena. Understandably, the principal/agent relationship, by definition, can be sometimes-antagonistic, especially when one realizes that the relationship may not always be voluntary. Young et al. (2012) furthered this linkage with their understanding of the age-adoption question as stated in pay-for-performance situations the agent is "assumed to be risk averse" (p. 965). Agency theory's "for this, you get that" nature suggests the agent in this case (the executive) will set the trade-off higher if they view the situation as risky.

\subsection{Significance of the Study}

Considerable prior research has been conducted into the benefits of a cloud computing strategy. While these benefits are undeniable, other research has shown that overall adoption has not been as widespread as could be expected. Low et al. (2011) concluded from their study that cloud adoption rates are "not growing as fast as expected" (p. 1007). An understanding of the age-adoption quandary was thought to possibly provide at least part of an explanation.

This researcher believed the results of this studycould provide additional clarification regarding the outcomes of previous research (Smith, Jr., 2016) wherein support was found for five hypotheses, namely, (a) advancement, recognition and satisfaction from accomplishments (positive), (b) top management support (positive), (c) diminishment of personal image (positive), (d) a pattern of technology readiness (positive), and (e) diminishment of personal image (negative) influence business intentions regarding the adoption of cloud computing applications. This amplification may assist the sales organizations within cloud computing services vendors to build more effective customer account strategies which, in turn, could lead to greater sales.

\section{Research Design}

\subsection{Problem Statement}


All of this research focused on the reasons why firms may be predisposed to choose or not choose the cloud option, but in the end, who makes the decision? While they may not always have ultimate decision-making authority, the IT executive's opinion and attitudes towards change are often the critical factors in the process. This researcher (2016) studied this adoption decision question. In his survey of 232 IT executives, he found support for five hypotheses:

- advancement, recognition and satisfaction from accomplishments (positive impact on adoption),

- top management support (positive impact),

- diminishment of personal image (positive impact),

- a pattern of technology readiness (positive impact), and

- diminishment of personal image (negative impact).

While these conclusions provide considerable insight into the adoption quandary, in and of themselves they are limited in their actionability. This realization has led this researcher to explore correlations between certain demographics and the associated level of cloud adoption. The first of these demographics to be studied is the age of the IT executive.

$\mathbf{R Q}_{1}$ : Is there a correlation between the age of an IT executive and the adoption level of cloud computing applications at their firm?

Inasmuch as the outcomes of the previous study centered on the concept of perceived risk, it appeared reasonable to this researcher that the perception could vary with the age of the IT executive. If true, this result could provide greater insights to sales organizations of cloud computing service providers when developing their pitches to prospective customers.

\subsection{Research Objectives}

This study collected data via a survey instrument from IT executives of U.S. companies concerning the number of applications they have outsourced to the cloud. The surveying process produced 232 responses from qualified participants. This response count represents $43.3 \%$ of the total survey distribution. This information was analyzed to determine if a relationship exists between IT executive age and the total number of applications outsourced to the cloud.

\subsection{Independent and Dependent Variables}

This study used oneindependent and one dependent variable. The independent variable was AGE BRACKET, a grouping of respondent ages (see below for details). The dependent variable was a calculated field (TOTAL_ADOPTION), representing the sum of the respondent's assessment oftheir adoption level of the following services:

- private or internal cloud,

- Software as a Service,

- Platform as a Service,

- Infrastructure as a Service,

- Communications as a Service,

- Storage as a Service,

- Network as a Service, and

- other.

\section{Methodology}

\subsection{Research Questions}

$\mathbf{R Q}_{\mathbf{1}}$ : Is there a correlation between the age of an IT executive and the adoption level of cloud computing applications at their firm?

\section{Hypothesis}

The purpose of this study was to determine whether there is a relationship between IT executive age and the overall adoption rate of cloud computing services. If such a relationship exists, it was expected the survey responses would indicate a negative correlation between IT executive age and cloud adoption levels for all cloud applications. One hypothesiswas tested, namely:

$\mathbf{H}_{\mathbf{0}}$ : All age groups have an equal level of adoption of cloudapplicationsas measured by the number of services and applications adopted.

$\mathbf{H}_{\mathbf{a}}$ : At least one age group differs in terms of level of adoption of cloud application. 


\subsection{Data Collection}

This researcher used the McGrath Wheel (McGrath \& Runkel, 1972) and McGrath's two-step process (McGrath, 1994) for selecting the most appropriate strategy for this study. As the first step, this researcher was required to determine where this study's environment was situated on the concrete vs. abstract axis. This step involved making an assessment of the degree to which the situation was universal (i.e., abstract) or particular (i.e., concrete). A similar assessment was made on the obtrusive vs. unobtrusive axis. In the second step, the researcher considered, relative to the desired outcome of the study, the three so-called A-B-C criterion (i.e., generalization, precision, and realism). According to McGrath (1994), the simultaneous maximization of all three criterion was not possible.

This researcher concluded that the study's setting was more concrete than abstract and, as such, would require obtaining information directly from the principals involved in the cloud adoption decision-making process. Accordingly, the strategy would require a moderately intrusive data collection procedure. It was realized that the procedure would have to respect the time pressures on these executives. These conclusions placed this study in the concrete/obtrusive quadrant of the McGrath Wheel, narrowing the choices from eight to two. In the second step of the process, the researcher concluded that the desired outcome for the study was to be as general in its applicability as possible. Consequently, the A-B-C criteria found in McGrath's process caused this researcher to conclude the survey option was preferable.

\subsection{Survey Instrument}

The survey instrument utilized questions derived from previously validated scales, the responses to which provided the dataset required for this assessment. Tashkandi and Al-Jabri's (2015) article on cloud computing adoption included 24 questions used in their instrument. Questions from this and other studies proved useful for the baseline content of the survey employed in the current study. Five-hundred fifty-six IT executives of companies located in the United States and representing various company sizes and industries received the questionnaire. The survey process produced 232 responses from qualified participants. This response count represents $43.3 \%$ of the total survey distribution.

\subsection{Data Analysis Methodology}

A quantitative method was utilized due to the nature of the problem statement. Inasmuch as the age variable data proved to be non-normally distributed (see "Testing for Normality"), the Spearman's Rank-order Correlation was used for testing purposes.

\section{Results}

\subsection{Response Rate}

The survey was distributed to 556 IT executives of companies located in the United States and representing various company sizes and industries. The survey process produced 232 responses from qualified participants. These replies represented a $43.3 \%$ participant response rate.

\subsection{Participant Demographics}

The mean age of the survey respondents was 34.98 years. In the respondent group, $73.9 \%$ were age 40 or less. See Figure 1.

\subsection{Dataset Modifications}

Twenty-one records were found to have incomplete data and it became necessary to remove those records from the dataset. This cleansing process reduced the number of records contained in the dataset from 232 to 211 .

\subsection{Inferential Statistics}

Testing for normality. The histogram and Q-Q plot suggested the age variable data distribution demonstrated signs of non-normality (see Figures 2 and 3). While the skewness, kurtosis, and standard error of kurtosis test results were within standards, the standard error of skewness test produced a result that exceeded the limit.

The hypotheses used for the normality test were:

$\mathbf{H}_{\mathbf{0}}$ : The sample data follow a normal population

$\mathbf{H}_{\mathbf{a}}$ : The sample data do not follow a normal population

With $\alpha=.05$,the K-S and the S-W tests both produceda.000 significance. Consequently,the researcherrejected the null hypothesis and concluded that the sample data does not follow a normal population. Therefore it was necessary to use a non-parametric test such as the Spearman's Rank-order Correlation to compare the two variables used in this study. 
Test of correlation. The researcher used six age brackets for the test of correlation, specifically: <36, 36-40, 41-45, 46-50, 51-55, and $>55$. These age brackets have been used in other studies such as Li, et al. (2006) and Li \& Tan (2013).Using Age Bracket and ADOPT_TOTAL as the independent and dependent variables, respectively, the Spearman's Rank-order Correlation test produced the results contained inFigure 6. For correlations such as Pearson, Spearman's, etc., significance is commonly defined as $p<.05$. With a value of .691, the correlation in this test is not statistically significant and it cannot be assumed the correlation differs from zero in the population.

\subsection{Presentation of Results}

The null hypothesis was tested with the Spearman's Rank-order Correlation test using age (in the form of "Age Bracket") as the independent variable and TOTAL_ADOPT as the dependent variable. Inasmuch as the significance produced by the test (.691) was not less than the value established for alpha (.05), the decision was to fail to reject the null hypothesis.

\section{Recommendations and Conclusions}

Considering the results of his previous study into personal decision factors related to the adoption of cloud solutions by IT executives (Smith, Jr., 2016), the results of this test were unexpected to this researcher. However, this test could be considered a first step in understanding the relationship between age and cloud adoption levels. Further study may be warranted to determine if the correlation changes with certain age brackets. For instance, the skewness found in this dataset towards a younger group of executives may have diminished the significance present in older age groups. A study to compare the correlation levels of the various age brackets may produce results that further an understanding of the previous study's conclusions.

\section{Tables and Figures}

\subsection{Tables}

\begin{tabular}{|l|l|l|l|}
\hline Test & Equation & Computed Value & Standard Value \\
\hline $\begin{array}{l}\text { Standard Error of } \\
\text { Skewness }\end{array}$ & $\begin{array}{l}\text { |Skewness| / Standard Error of Skewness } \\
\text { (Skewness) }\end{array}$ & 5.988 \\
\hline $\begin{array}{l}\text { Standard Error of } \\
\text { Kurtosis }\end{array}$ & $\begin{array}{l}\text { Kurtosis| / Standard Error of Kurtosis } \\
\text { (Kurtosis) }\end{array}$ & .339 & $<2$ \\
\hline Skewness & $\begin{array}{l}\text { Skewness } \mid \\
\text { Kurtosis }\end{array}$ & 1.002 & $<3$ \\
\hline Range Test & Standard Deviation / Range & .336 & $<3$ \\
\hline
\end{tabular}

Table 1. Normality test results.

\subsection{Figures}

\begin{tabular}{|r|c|r|r|r|}
\hline & AGE BRACKET & COUNT & PERCENT \\
\cline { 2 - 5 } & $-<36$ & $<36$ & 137 & $64.9 \%$ \\
\hline & $-36-40$ & $36-40$ & 22 & $10.4 \%$ \\
$-41-45$ & $41-45$ & 19 & $9.0 \%$ \\
$-46-50$ & $41-55$ & $46-50$ & 10 & $4.7 \%$ \\
\hline & $51-55$ & 11 & $5.2 \%$ \\
\hline & $>55$ & 12 & $5.7 \%$ \\
\hline
\end{tabular}

Figure 1. Age breakdown of respondent groups. 


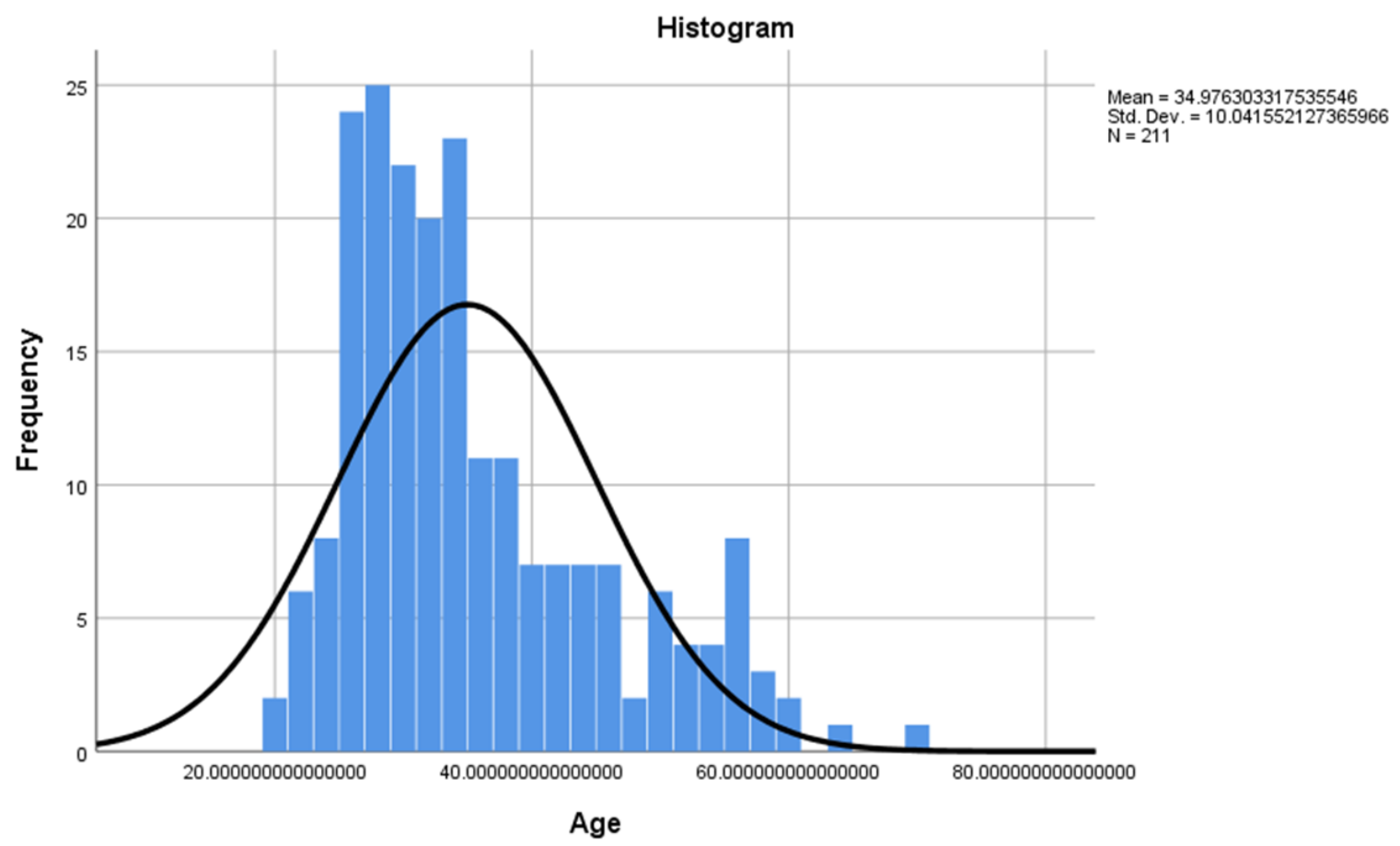

Figure 2. Histogram of the age variable data distribution.

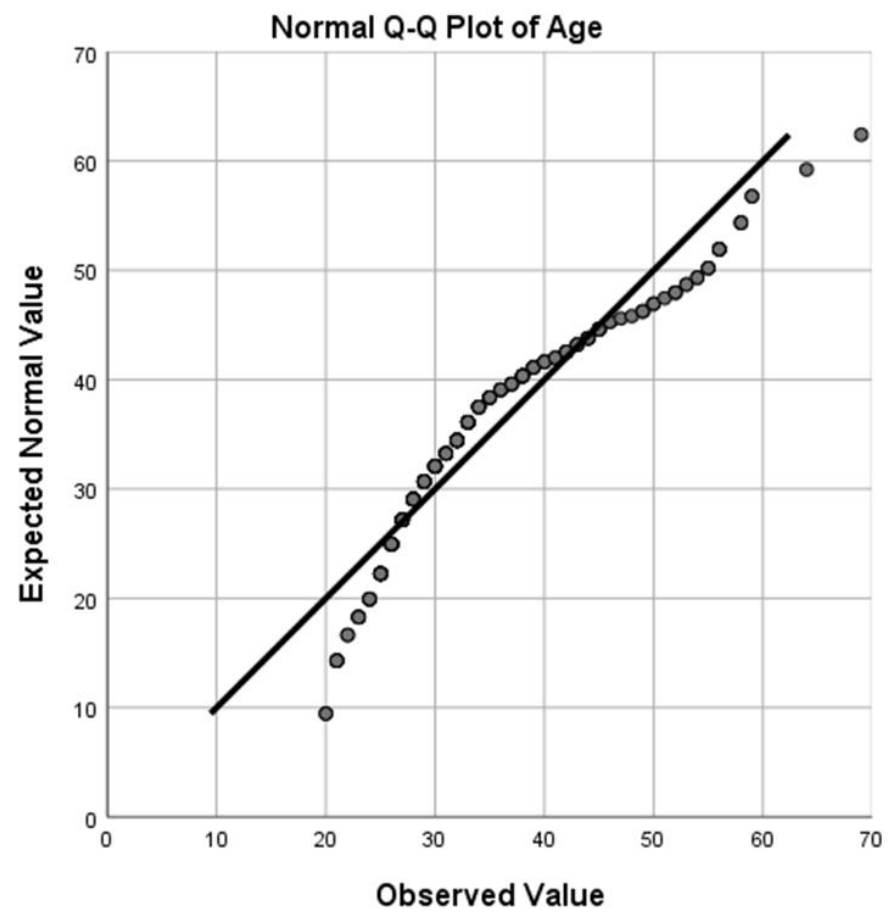

Figure 3. Q-Q plot of the age variable data distribution. 


\section{Statistics}

\begin{tabular}{|c|c|c|}
\hline \multicolumn{3}{|c|}{ Age } \\
\hline \multirow[t]{2}{*}{$N$} & Valid & 211 \\
\hline & Missing & 0 \\
\hline \multicolumn{2}{|c|}{ Mean } & 34.97630332 \\
\hline \multicolumn{2}{|c|}{ Median } & 32.00000000 \\
\hline \multicolumn{2}{|c|}{ Std. Deviation } & 10.04155213 \\
\hline \multicolumn{2}{|c|}{ Skewness } & 1.002 \\
\hline \multicolumn{2}{|c|}{ Std. Error of Skewness } & .167 \\
\hline \multicolumn{2}{|c|}{ Kurtosis } & .336 \\
\hline \multicolumn{2}{|c|}{ Std. Error of Kurtosis } & .333 \\
\hline \multicolumn{2}{|c|}{ Range } & 49.00000000 \\
\hline
\end{tabular}

Figure 4. Statistics from the age variable data distribution.

\section{Tests of Normality}

\begin{tabular}{lc|c|c|c|c|c} 
& \multicolumn{2}{c|}{ Kolmogorov-Smirnov } & \multicolumn{3}{c}{ Shapiro-Wilk } \\
& Statistic & \multicolumn{1}{c}{ df } & \multicolumn{1}{c}{ Sig. } & Statistic & \multicolumn{1}{c}{ df } & \multicolumn{1}{c}{ Sig. } \\
\hline Age & .161 & 211 & .000 & .910 & 211 & .000 \\
\hline
\end{tabular}

\section{a. Lilliefors Significance Correction}

Figure 5. Results of the K-S and Shapiro-Wilk tests on the age variable data distribution.

\begin{tabular}{|c|c|c|c|c|}
\hline \multicolumn{5}{|c|}{ Correlations } \\
\hline & & & Age Bracket & $\begin{array}{c}\text { ADOPT_TOTA } \\
\text { L }\end{array}$ \\
\hline \multirow[t]{6}{*}{ Spearman's rho } & \multirow[t]{3}{*}{ Age Bracket } & Correlation Coefficient & 1.000 & -.027 \\
\hline & & Sig. (2-tailed) & . & .691 \\
\hline & & $\mathrm{N}$ & 211 & 211 \\
\hline & \multirow[t]{3}{*}{ ADOPT_TOTAL } & Correlation Coefficient & -.027 & 1.000 \\
\hline & & Sig. (2-tailed) & .691 & . \\
\hline & & $\mathrm{N}$ & 211 & 211 \\
\hline
\end{tabular}

Figure 6. Results of the Spearman's Rank-order Correlation test on Age Bracket and ADOPT_TOTAL variables. 


\section{References}

Deci, E., \& Ryan, R. (1980). The empirical exploration of intrinsic motivational processes. In L. Berkowitz, \& L. Berkowitz (Ed.), Advances in experimental social psychology (Vol. 13, pp. 39-80). Academic Press.

Dhar, S. (2012). From outsourcing to Cloud computing: evolution of IT services. Management Research Review, 664675.

Espandal, M., \& Oliveira, T. (2012). Cloud computing adoption: Determinants of cloud computing adoption by firms. MCIS 2012 Proceedings (pp. 1-10). Guimaraes, Portugal: AIS Electronic Library.

Hambrick, D. C., \& Mason, P. A. (1984). Upper echelons: The organization as a reflection of its top managers. Academy of Management, 193-206.

Koeber, C., \& Wright, D. W. (2001). Age bias in worker displacement: How industrial structure shapes the job loss and earnings decline of older American workers. Journal of Socio-Economics, 343-352.

Li, Y., \& Tan, C. (2013). Matching business strategy and CIO characteristics: The impact on organizational performance. Journal of Business Research.

Li, Y., Tan, C., Teo, H., \& Tan, B. (2006). CIOs of all ages and tenure cannot afford to insulate themselves from new technologies and innovations. IEEE Transactions on Engineering Management.

Lippmann, S. (2008). Rethinking risk in the new economy: Age and cohort effects on unemployement and reemployment. Human Relations, 1259-1292.

Low, C., Chen, Y., \& Wu, M. (2011). Understanding the determinants of cloud computing adoption. Industrial Management \& Data Systems, Vol. 111 No. 7, 1006-1023.

McGrath, J. (1994). Methodological matters: Doing research in the behavioral and social sciences. In Readings in Human-Computer Interaction: Toward the Year 2000 (2nd ed., pp. 152-169). San Francisco, CA: Morgan Kaufmann.

McGrath, J., \& Runkel, P. (1972). Research on human behavior: A systematic guide to method. New York, NY: Holt, Rinehart and Winston.

Mell, P., \& Grance, T. (2011). The NIST Definition of Cloud Computing. National Institute of Standards and Technology (NIST).

Oliveira, T., Thomas, M., \& Espandal, M. (2014). Assessing the determinants of cloud adoption: An analysis of the manufacturing and service sectors. Information \& Management, 497-510.

Prescott, R. (2011, August 16). Cloud computing is in its infancy, Gartner VP says. Retrieved April 9, 2014, from www.rcrwireless.com: http://www.rcrwireless.com/article/20110816/enterprise/cloud-computing-is-in-itsinfancy-gartner-vp-says/

Serfling, M. (2015). CEO age and the riskiness of corporate policies. Journal of Corporate Finance, 251-273.

Smith, Jr., M. L. (2016). "Personal Decision Factors Considered by Information Technology Executives: Their Impacts on Business Intentions and Consequent Cloud Computing Services Adoption Rates". San Antonio: Dissertation, University of the Incarnate Word.

Smith, Jr., M. L., \& Gonzalez, M. D. (2014). Are Cloud Computing Adoption Trends Changing. Franklin Law.

Young, G., Beckman, H., \& Baker, E. (2012). Financial incentives, professional values and performance: A study of pay-for-performance in a professional organization. Journal of Organizational Behavior, 33, 964-983.

\section{Author's Biography}

Dr. Marcus L. Smith, Jr., is an Assistant Professor at Texas A\&M-Commerce University. Prior to his career in higher education, Dr. Smith served as Chief Technology Strategist for AT\&T as well as the lead IT executive for multiple companies over more than twelve years. Dr. Smith has worked also for three major consulting firms where he developed frameworks and methodologies for IT-related strategic planning. His total body of career experiences represents a combination of consulting best practices and the work of an industry practitioner. 